Antropólogo visual, artista e professor de Artes e Antropologia na EACH-USP. Doutor em Antropologia Socia pela École des Hautes Études en Sciences Sociales (EHESS/Paris), com pós-doutorado pelo Departamento de Multimeios do Instituto de Artes da Unicamp. Pesquisador associado do departamento de Antropologia da Goldsmith (Londres) e colaborador do Fórum Permanente (ECA-USP). Autor de Diário acadêmico.

\title{
Novos ataques de ZEVS contra a Sociedade Global de Decepção
}

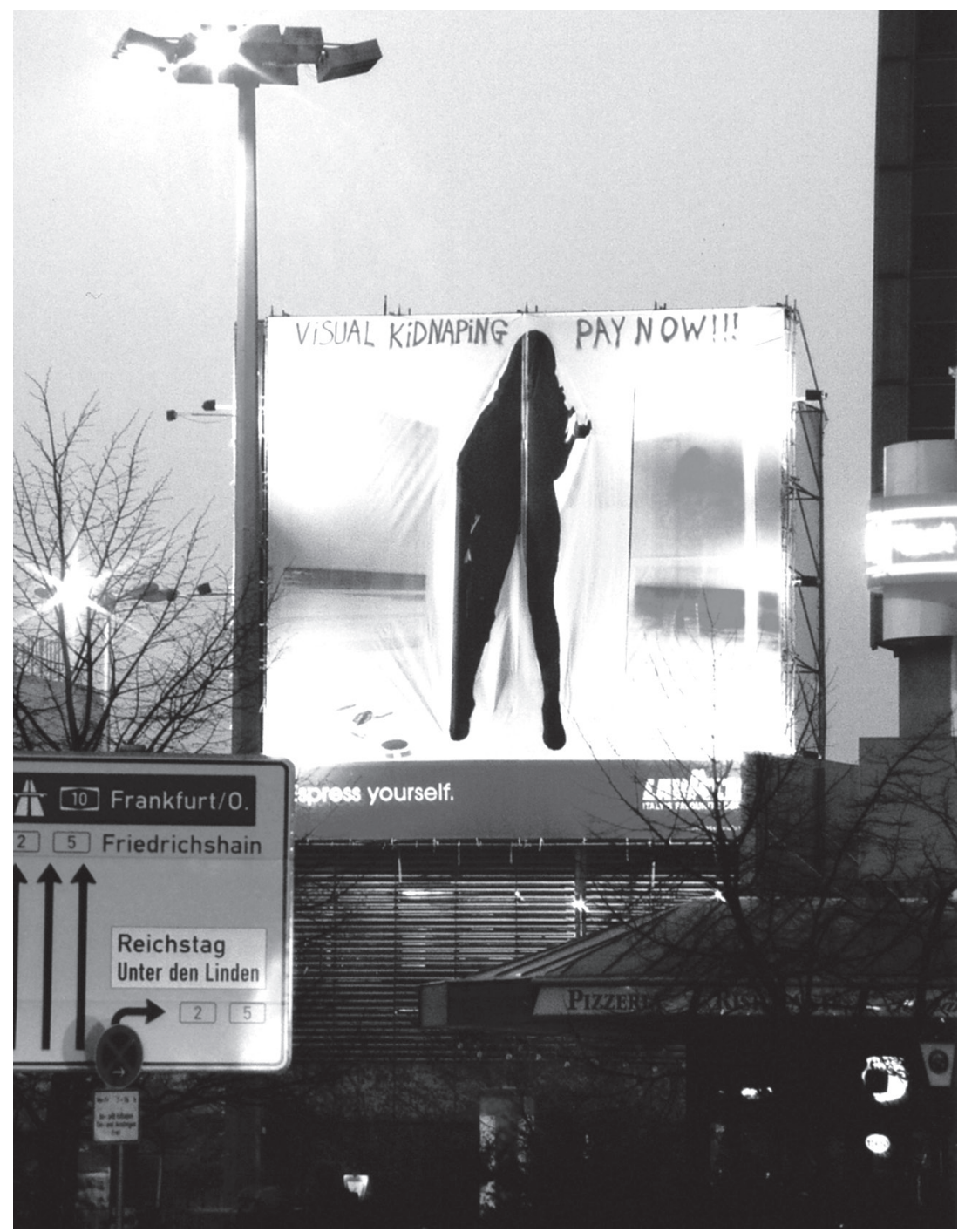

O olho de Zeus vê tudo, conhece tudo Hesíodo

Ao escapar de um acidente fatal no RER ZEVS (trem urbano da rede de metrô de Paris), o artista francês ZEVS, filho dos transportes públicos, da eletricidade e da cidade, transformou radicalmente o seu processo artístico e começou a ver a cidade e seus fantasmas de uma forma mais intensa, mais violenta e talvez mais justa: olho por olho. Nos seus dias tensos e artisticamente férteis, o bem-estar da sociedade de decepção descrita por Gilles Lipovetsky (2007) depende das suas boas vontades e dos seus 
ataques de raiva. Através dos seus ataques visuais (VISUAL ATTACKS, 2001), dos seus VISUAL KIDNAPPING (2002-2004) e mais recentemente dos seus logos assassinados (LIQUIDATED LOGOS, 2006), ZEVS ataca o espaço publicitário urbano, armado dos seus raios conceituais, das suas ferramentas de artista urbano e de alguns pigmentos - seu reino é o mundo globalizado das multinacionais, das cidades genéricas, das imagens que invadem os espaços urbanos e as mentes dos cidadãos contemporâneos.

Como na maiêutica de Sócrates, ZEVS ajuda o parto das consciências maltratadas pelo hiperconsumo e pelo delírio generalizado das mídias, característicos da nossa "sociedade de decepção". Ao ajudar a desvendar o que se esconde atrás das grandes marcas contemporâneas, o artista se transforma num tipo de justiceiro pós-moderno, sempre pronto para lutar contra o poder das grandes marcas, o reino incondicional do materialismo e o fascínio do consumo globalizado. Seus gestos de artista, realmente e simbolicamente violentos, desviam os ícones da comunicação capitalista num excesso de raiva criativa. Os titãs são as poderosas marcas da sociedade de consumo e ZEVS maltrata com muita eficácia seus corpos emblemáticos, seus logotipos e suas musas.

Na verdade, tal como o famoso Andy Warhol e a sua "pop arte", ZEVS sempre soube escolher bem suas marcas-vitimas, seus inimigos capitalistas, sobre os quais ele vai deixar suas próprias marcas: suas obras. Engajado e atacado, o artista conhece bem essas marcas e seus pontos fracos... Assalto frontal dos outdoors urbanos em 2001, kidnapping da musa do café Lavazza em 2002, ZEVS humaniza as marcas e as suas diversas imagens (de marca) levando-as aos limites da violência simbólica - ele mostra as marcas sangrando, derretendo, chorando, evidenciando seus maus-tratos para abrir nossos olhos. ZEVS sempre ataca com a mesma força as três funções do logotipo - sua função expressiva e representativa é desviada, sua função referencial e informativa é pervertida, sua função empática muda de público-alvo. Em seus ataques, ZEVS faz com que os logotipos sejam as vítimas metonímicas das próprias empresas multinacionais, consciente de que, desde o primeiro logotipo, o monograma do Cristo em grego XP, as redes de imagens de marca se multiplicarão tais como parasitas urbanos.

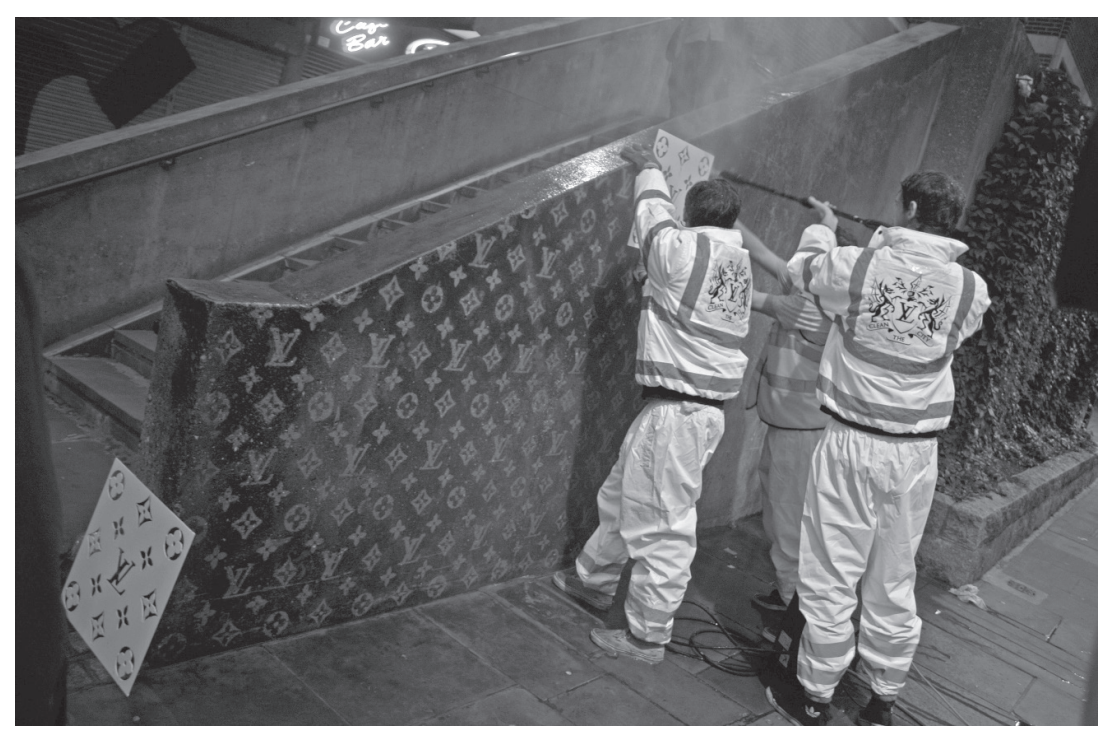

Lipovetsky (2007, p. 233) alerta:

Dizem que a sociedade de consumo nos condena a viver num estado permanente de frustração, que ela fabrica com eficácia a insatisfação de todos (...) Mas, esses fenômenos são também acompanhados de um poderoso desejo de sair desta passividade uma vontade de entender e uma curiosidade crescente (...)

Nesse contexto de resistência cultural, ZEVS propõe suas reflexões conceituais sobre o mundo contemporâneo, sobre a religião das marcas e sobre as batalhas selvagens dos titãs capitalistas. Numa tentativa de comunicação direta e eficaz nos suportes ready-mades das marcas contemporâneas, ZEVS liquida literalmente os logotipos sem deixar de revelar as suas identidades, já que mesmo depois das suas intervenções pode-se reconhecer a marca-vítima. Ao assassinar em série os modelos e outras 
musas capitalistas, ele tenta salvar suas almas do Universo do Olímpio das Multinacionais - Apple, Coca-Cola, McDonald's, Armani, Chanel, Louis Vuitton, UBS, Lacoste, Malboro, Playboy, Nike, CNN. As vítimas são sempre conhecidas e famosas, e os danos, bem visiveis.

Vendo suas obras atuais, podemos entender de que forma sua formação de street art deixou suas garras e como sua estética mudou após seu bad trip no trem regional de Paris. De fato, ZEVS controla com muito talento a retórica das marcas e a semiótica dos logotipos. Tal qual outro Magritte, ele consegue maltratar as marcas contemporâneas criando uma nova imagem, cujo sentido é revelado ao público através das conotações e de outros arranhões. Sua obra pode aproximar-se eticamente e esteticamente do artista francês Yves Klein, mas sua vontade de vingança e sua atividade crítica se parecem mais com a estética relacional de Félix Gonzales-Torres. Do topo do seu mirante urbano, sempre acompanhado da águia da Ferrari, ZEVS observa as ações inumanas das marcas contemporâneas buscando uma nova forma de contrapoder. Olho por arte, arte pelo olho.

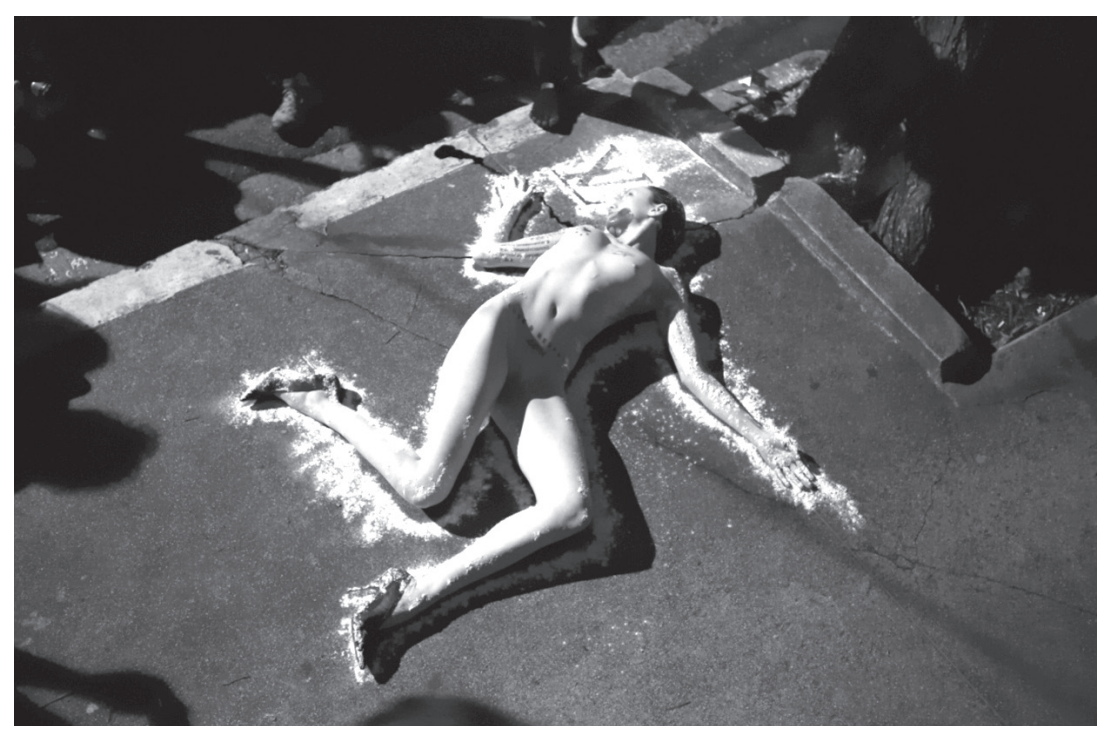

Quando o auxiliei na produção de sua performance nos Jardins, em São Paulo, onde todas as grandes marcas (de luxo) ostentam suas lojas, constatei que 0 artista não faz de conta, mas vai fundo nas suas visões e vai além: não tem piedade. Meia-noite, rua vazia, vento mórbido. Uma top model brasileira coberta de tatuagens é assassinada friamente num banho de sangue. Essa mulher nua não foi sacralizada como nas Antropometrias azuis de Klein. Nua, ferida e abandonada no asfalto mais chique da cidade, ela espera os jornalistas de moda para voltar à vida e conhecer uma vida após a morte. Simples manequim, sujeito-objeto simbólico, puro simulacro, ela é desmistificada e violentada em frente às marcas que a amparavam. As lojas fechadas, vigiadas e silenciosas, parecem conter suas respirações. E quem sabe qual será a próxima vítima desse novo "deus" da arte urbana?

[1] ZEVS é representado pela Galeria Patrícia Dorfman, em Paris. Saiba mais em: www.patriciadorfmann. com/artist/zevs. Veja também o website do artista francês (www.gzzglz.com) que, de forma sádica e irônica, ataca as famosas páginas do Google.

\section{REFERÊNCIA}

LIPOVETSKY, Gilles. A felicidade paradoxal: ensaio sobre a sociedade de hiperconsumo.

São Paulo: Companhia das Letras, 2007 